\title{
Thermoelectric Module Performance in Cryogenic Temperature*
}

\author{
Mitsuru KAMBE**, Ryo MORITA**, Kazuyuki OMOTO***, Yasuhiro KOJI***, \\ Tatsuo YOSHIDA**** and Koji NOISHIKI**** \\ ${ }^{* *}$ Central Research Institute of Electric Power Industry (CRIEPI) \\ 2-11-1, Iwado-kita, Komae-shi, Tokyo, 201-8511 JAPAN \\ E-mail: kambe@criepi.denken.or.jp \\ ***The Kansai Electric Power Co., Inc. \\ 3-11-20, Nakoji, Amagasaki, Hyogo, 661-0974 JAPAN \\ ****Kobe Steel, Ltd.
}

2-3-1, Shinhama, Arai-cho, Takasago-city, Hyogo, 676-8670 JAPAN

\begin{abstract}
Performance of thermoelectric (TE) modules for the TE power conversion system combined with open rack type LNG vaporizer (ORV) is discussed. Most of the conventional BiTe TE modules suffer sudden decrease of the power at cryogenic temperature as low as $-160^{\circ} \mathrm{C}$. This is called as Mayer-Marschall effect. Authors investigated the cause of this effect and found TE modules that could avoid such effect. Performance data of such TE modules obtained at the cryogenic thermoelectric (CTE) test rig which could realize temperature and fluid dynamic condition of the ORV is presented.
\end{abstract}

Key words: Thermoelectric Module, Bismuth-telluride, Cryogenic, Liquefied Natural Gas, LNG, LNG Vaporizer, Open Rack Type Vaporizer, ORV

\section{Introduction}

The thermoelectric (TE) system is so far applied to the temperature gradient from room temperature to higher temperature, usually several hundreds degrees Celsius. Several TE semiconductors are available depending on the operating temperature, For example, silicon-germanium $(\mathrm{SiGe})$ performs best at the high temperatures $\left(\right.$ over $600^{\circ} \mathrm{C}$ ), while zinc-antimony $(\mathrm{ZnSb})$ achieves greatest effectiveness at intermediate temperatures $\left(200-500^{\circ} \mathrm{C}\right)$, and bismuth-telluride $(\mathrm{BiTe})$ has excellent performance at lower temperatures (room temperature to $200^{\circ} \mathrm{C}$ ). BiTe can also function as spot coolers when operated in reverse. On the other hand, published papers on the TE module performance at the temperature gradient from room temperature to cryogenic temperature are scarcely available.

The LNG power station is equipped with the LNG vaporizers to evaporate LNG of $-160^{\circ} \mathrm{C}$. LNG vaporizer is designed to re-gasify cryogenic LNG by a heat exchanger in which sea water is used as a heat source. In the former paper ${ }^{1}$, the authors proposed to make use of this temperature gradient i.e. $-160^{\circ} \mathrm{C}$ to room temperature by thermoelectric power conversion system (TE system) and presented a conceptual design of the TE system combined with open rack type LNG vaporizer. The system performance analysis has been made based on the TE module performance data obtained at the cryogenic thermoelectric (CTE) test rig which could realize temperature and fluid dynamic condition of the open rack type LNG vaporizer. Conventional BiTe TE modules of various manufactures were tested. In this investigation, we found that most of the conventional BiTe TE modules suffer 
sudden decrease of the power at cryogenic temperature as low as $-160^{\circ} \mathrm{C}$. We called it as Mayer-Marschall effect, however, the cause of this effect was not investigated yet.

In this paper, the investigation on the Mayer-Marschall effect conducted so far is described. The authors clarified the mechanism of this effect and found TE modules that could avoid such effect and provide excellent performance in cryogenic temperature. Performance data of such TE modules are presented.

\section{Thermoelectric Module Performance in Cryogenic Temperature}

\subsection{Sudden decrease of module power in cryogenic temperature (Mayer-Marschall} effect)

Conventional BiTe TE modules with and without container were tested. The TE module (type L) adopted is a 111 couples skeleton type, measures $40 \times 35 \mathrm{~mm}$ and $3 \mathrm{~mm}$ thick, manufactured by Ferrotec Corporation, as shown in Fig.1. The encapsulated TE module in which this TE module is encased is shown in Fig.2. It features vacuum tight and heat resistant up to $700^{\circ} \mathrm{C}$. Because inside of the container is kept vacuum, the stainless steel (SUS316) top container of $0.1 \mathrm{~mm}$ thick always exerts pressing load on the TE module by the difference pressure of $0.1 \mathrm{MPa}$, which results in reduction of thermal contact resistance in the container and accordingly enhance module performance independent of the operating temperature.

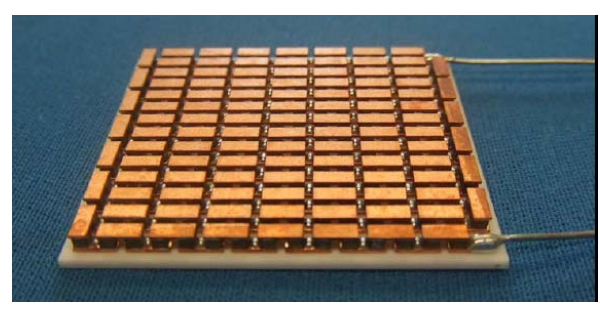

Fig.1 TE module (type L)

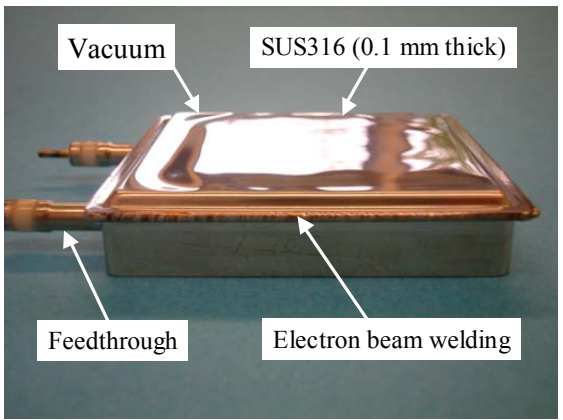

Fig.2 Encapsulated TE module

Measurement has been done in the vacuum chamber in which a heater block and cold plate as well as instrumentations are equipped, as shown in Fig. 3. Due to safety reasons, liquefied nitrogen $\left(-196^{\circ} \mathrm{C}\right)$ is adopted instead of LNG $\left(-160^{\circ} \mathrm{C}\right)$ to cool the cold plate. The vacuum chamber could avoid icing on the TE module during measurement. The external electrical resistance of the circuit was adjusted as $0.8-1.1 \Omega$ which is equal to the module internal resistance because the maximum module power is available in this condition. To exert temperature gradient, the module was sandwiched between the heater block and the cold plate with a pressing force of $50 \mathrm{~N}$. Silicon grease layers on the module top and bottom surfaces could reduce the thermal contact resistance at the interfaces. The module hot side temperature was measured by a thermocouple inserted in the heater block hole which is in the extreme vicinity of the module hot side. Similarly the module cold side temperature was obtained by another thermocouple inserted in the cold plate hole in the extreme vicinity of the module cold side. Thermocouples adopted were K type (class 1 ) with the accuracy \pm 1.5 $\mathrm{K}$ in the range down to $-60^{\circ} \mathrm{C}$. Calibration using liquid nitrogen $\left(-196^{\circ} \mathrm{C}\right)$, however, ensured that it has practically sufficient accuracy in the cryogenic temperature range of interest.

Module performance data are shown in Figs. 4-6. In these figures, the module voltage at open circuit is shown plotted as $\mathbf{U}(\mathrm{mV})$, while the module current at closed circuit and the module power are shown as $\mathbf{I}(\mathrm{mA})$ and $\mathbf{N}(\mathrm{mW})$, respectively. As shown in Fig. 4 , the module power increases as the cold side temperature decreases while maintaining the hot side as room temperature. At the cold side temperature $-180^{\circ} \mathrm{C}$, however, sudden decrease of the module power happens. In this instance one could hear a sharp acoustic signal "click" 
through the vacuum chamber. It is obvious that something happens in the module. This is called as "Mayer-Marschall effect" named after the finders.
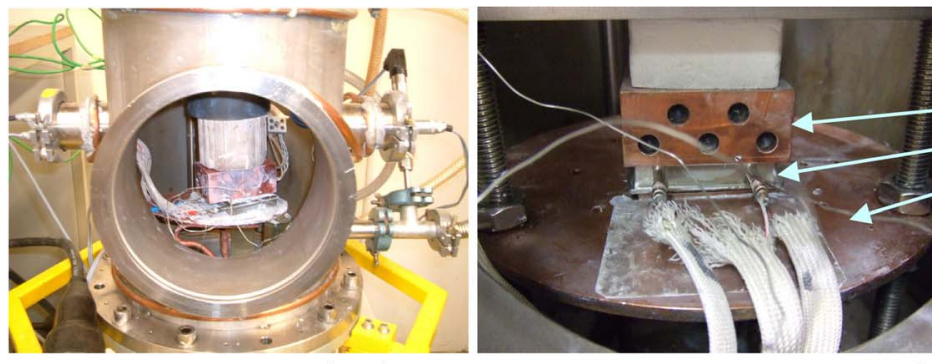

Heater block

Module

Cold plate

Vacuum chamber (left) and inside view of the chamber (right)

Fig.3 Vacuum chamber for module performance measurement

Similar effect is also perceived on the encapsulated module (L03) as shown in Fig. 5. On repeating the measurement, almost the same performance data was obtained and this effect also occurred again. Visual inspection and the module internal resistance measurement on these modules revealed that no damage was occurred on the modules.

Note that a ceramic plate of the skeleton module is in the cold side in case of Fig. 4 and 5. Then the encapsulated module (L03) is again measured in reverse temperature gradient, i.e. the ceramic plate on the hot side. This time such effect did not occur and the module power increases until the module cold side temperature $-190^{\circ} \mathrm{C}$ as shown in Fig. 6 .

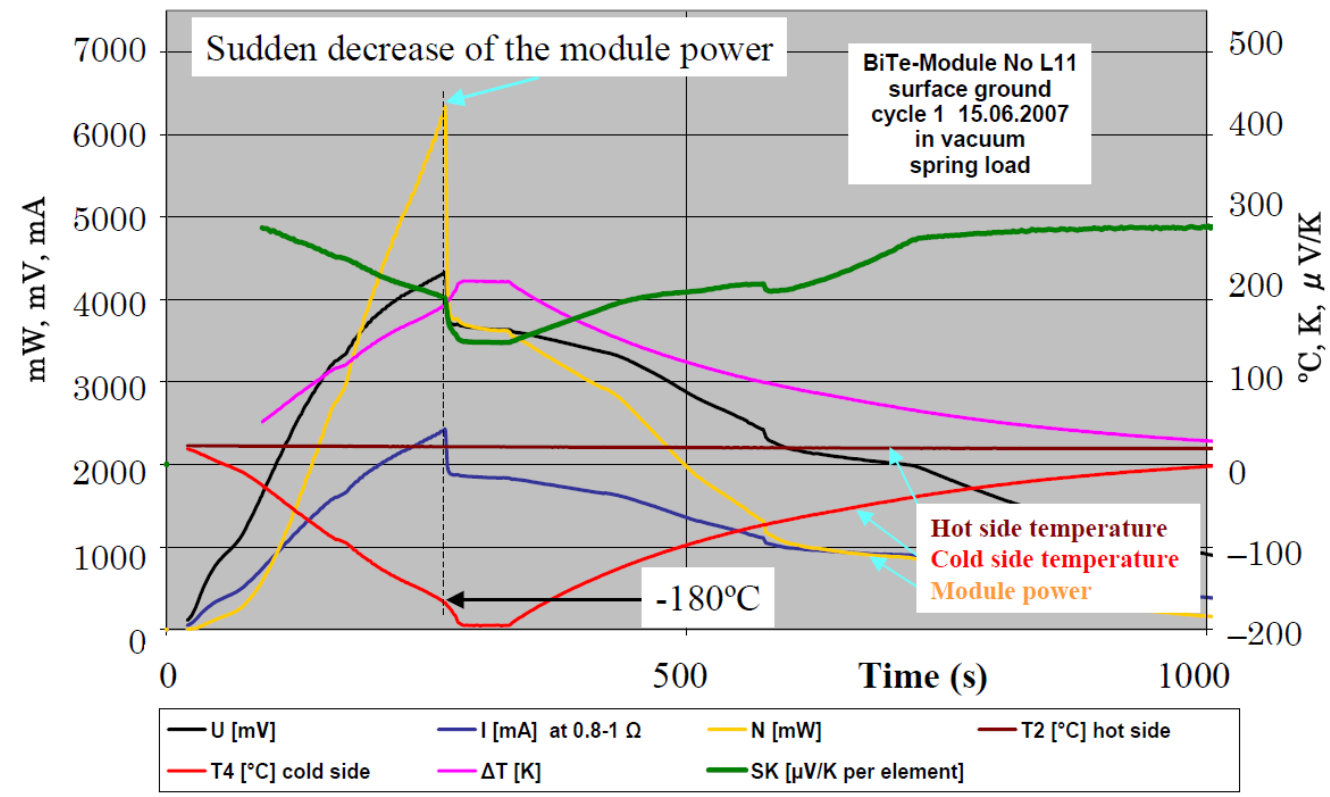

Fig.4 Sudden decrease of the module power (module L11 without container) 


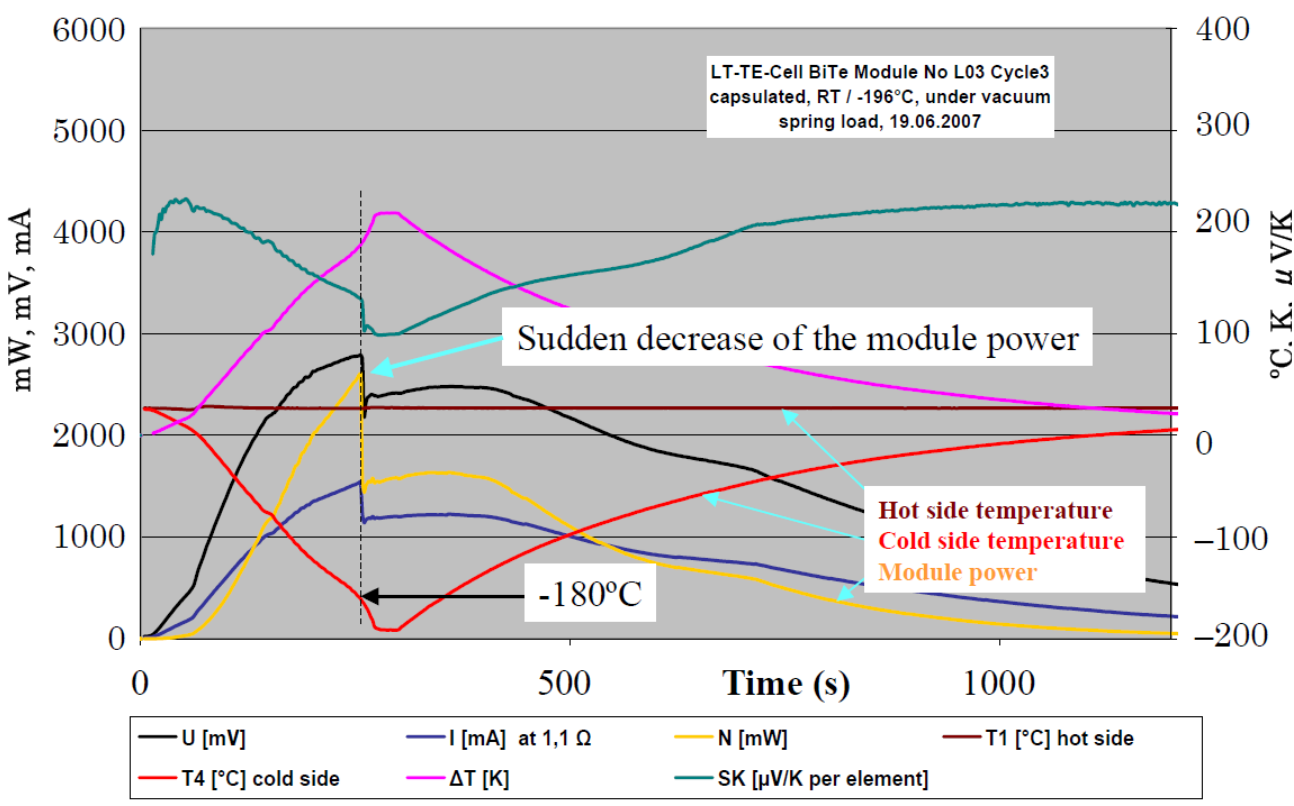

Fig.5 Sudden decrease of the module power (Encapsulated module L03)

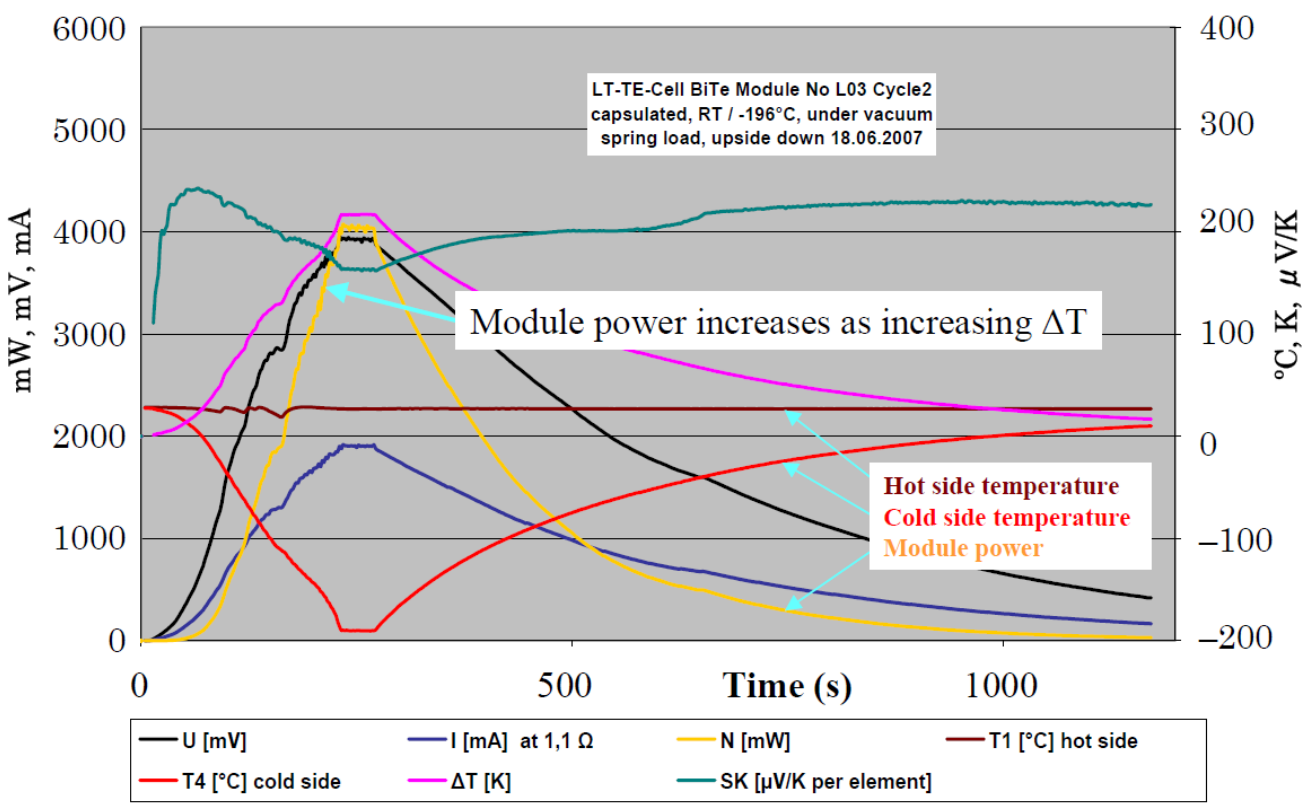

Fig.6 Module performance in reverse temperature gradient (Encapsulated module L03)

Measurement on the encapsulated modules has also been conducted at the cryogenic thermoelectric (CTE) test rig which could realize temperature and fluid dynamic condition of the ORV. A schematic and photo of the CTE test rig are shown in Figs. 7 and 8 , respectively. 


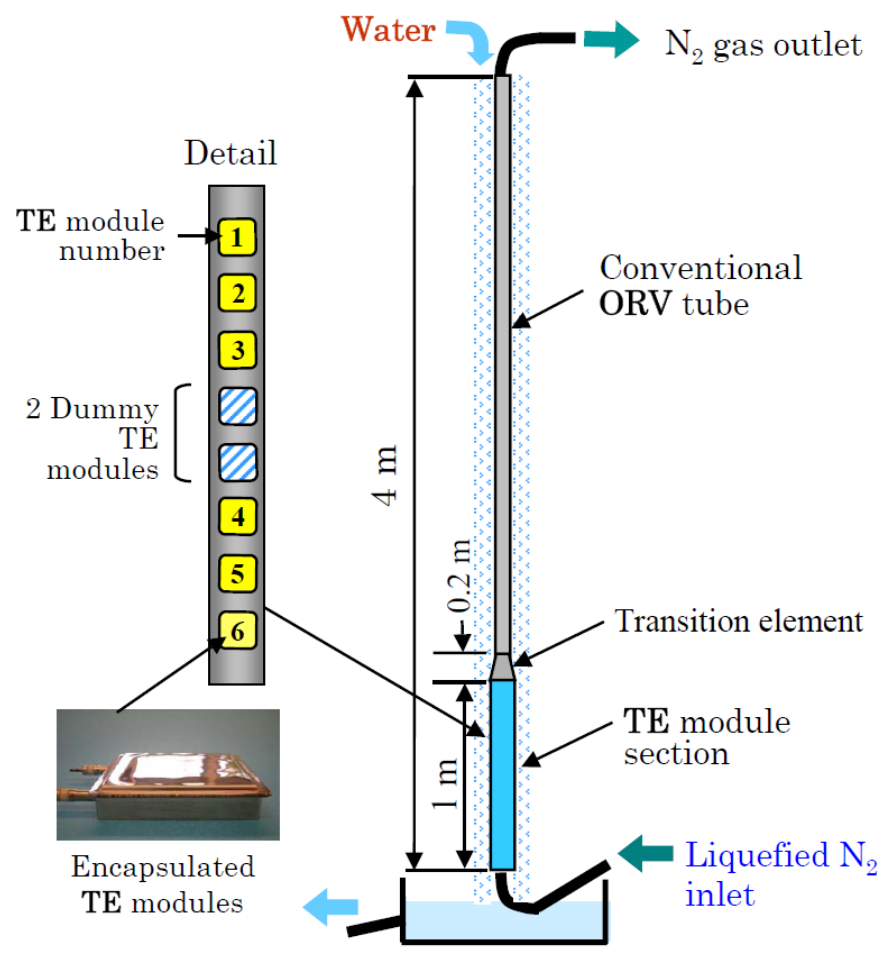

Fig.7 Schematic of the CTE test rig

Due to restriction of the laboratory, the overall length of the tube is $4 \mathrm{~m}$ instead of actual length of our design $(7 \mathrm{~m})$. However, it is sufficient for the purpose of the experiment because water supplied at the top of the ORV tube would accelerate its velocity as flows down on the tube surface and attain its maximum velocity (approximately $3 \mathrm{~m} / \mathrm{s}$ ) within $1 \mathrm{~m}$ from the top. Therefore we are sure that this test rig could achieve actual water flow situation on the TE module section. Liquefied nitrogen $\left(-196^{\circ} \mathrm{C}\right)$ is adopted instead of LNG $\left(-160^{\circ} \mathrm{C}\right)$ due to safety reasons. Further detail of the CTE test rig is described in our former paper [1]. The TE module section has 6 encapsulated TE modules (No.1-6, correspond modules L01-06, respectively) and 2 dummy TE modules (only containers without TE modules).

Module performance data at the CTE test rig is presented in Fig. 9. Test has been conducted by circulating water of room temperature around the tube while supplying liquefied nitrogen into the tube from the bottom, then module power increases as increasing temperature difference between the hot and cold side of the TE module. When the cold side of the module No.6 reached at $-110^{\circ} \mathrm{C}$, however, sudden decrease of the module power occurred as shown in Fig. 9. After that, other modules presented similar effect. Modules placed in the lower part of the TE module section (i.e. No. 4-6) suffer severe decrease of the module power. While the modules placed in the upper part of the TE module section (i.e. No. 1-3) show not so severe effect and the module power again increases soon. It is obvious that the module exposed to severe cooling gradient suffers severe Mayer-Marschall effect. In contrast with the module performance measurements in the vacuum chamber (i.e. Figs. 4 and 5), the Mayer-Marschall effect occurred at relatively higher temperature range (between -70 to $-120^{\circ} \mathrm{C}$ ) in the CTE test rig.

Based on these data, we can deduce that deformation of the module due to the severe thermal gradient in the thickness direction (over $200 \mathrm{~K} / \mathrm{mm}$ ) especially in the cryogenic temperature in which creep deformation can not be expected might be the cause of the Mayer-Marschall effect. Difference between the module performance test in the vacuum 
chamber and the CTE test rig is illustrated in Fig. 10. The module in the former is sandwiched between a rigid heater block and a cold blocks. While in the latter case, the module deformation is easier because water exerts pressing force of 1 bar $(0.1 \mathrm{MPa})$ instead of a rigid heater block. This coincides well with the fact that the Mayer-Marschall effect occurred at smaller $\Delta \mathrm{T}$ in the CTE test rig.

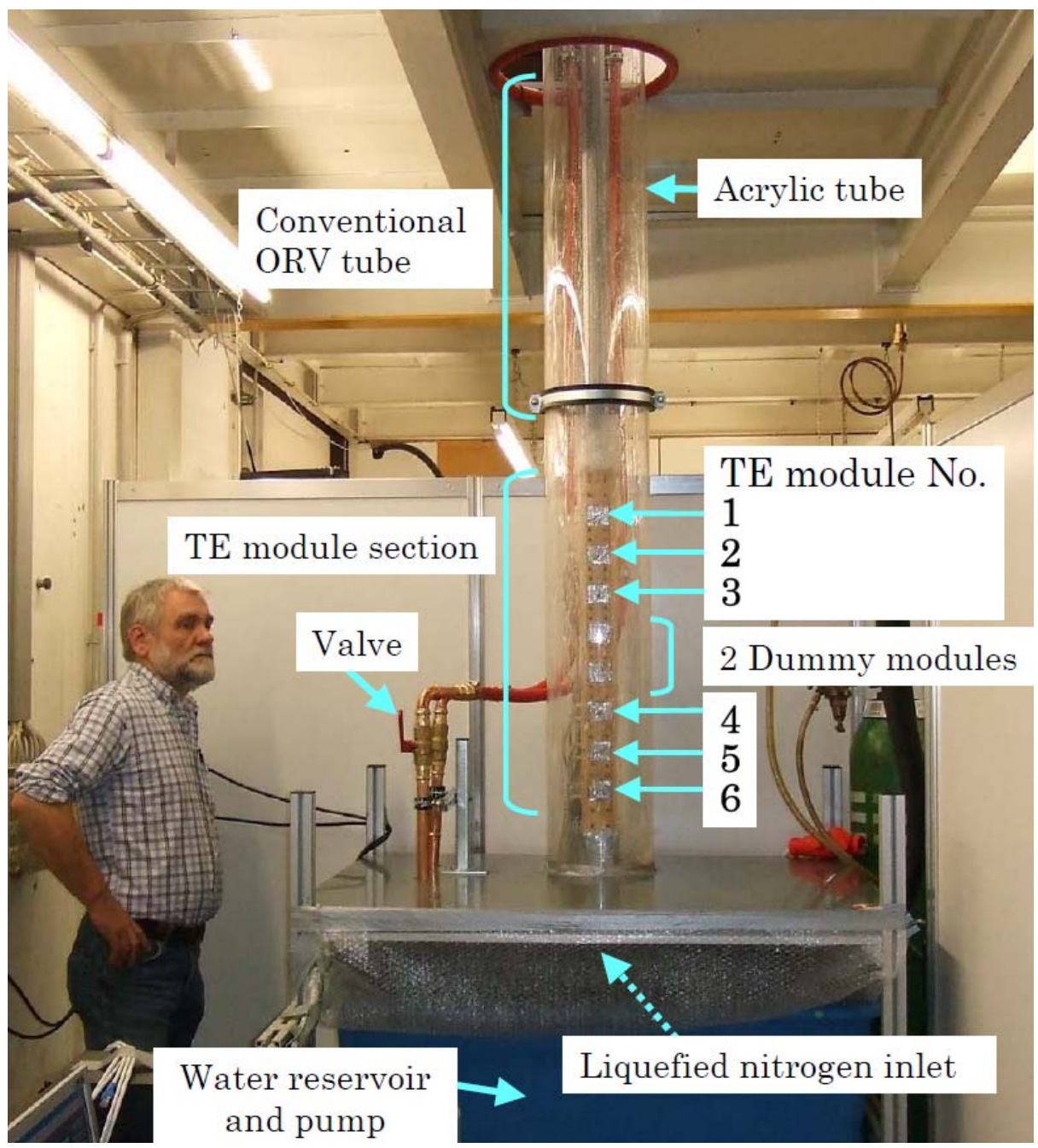

Fig.8 Overview of the CTE test rig 

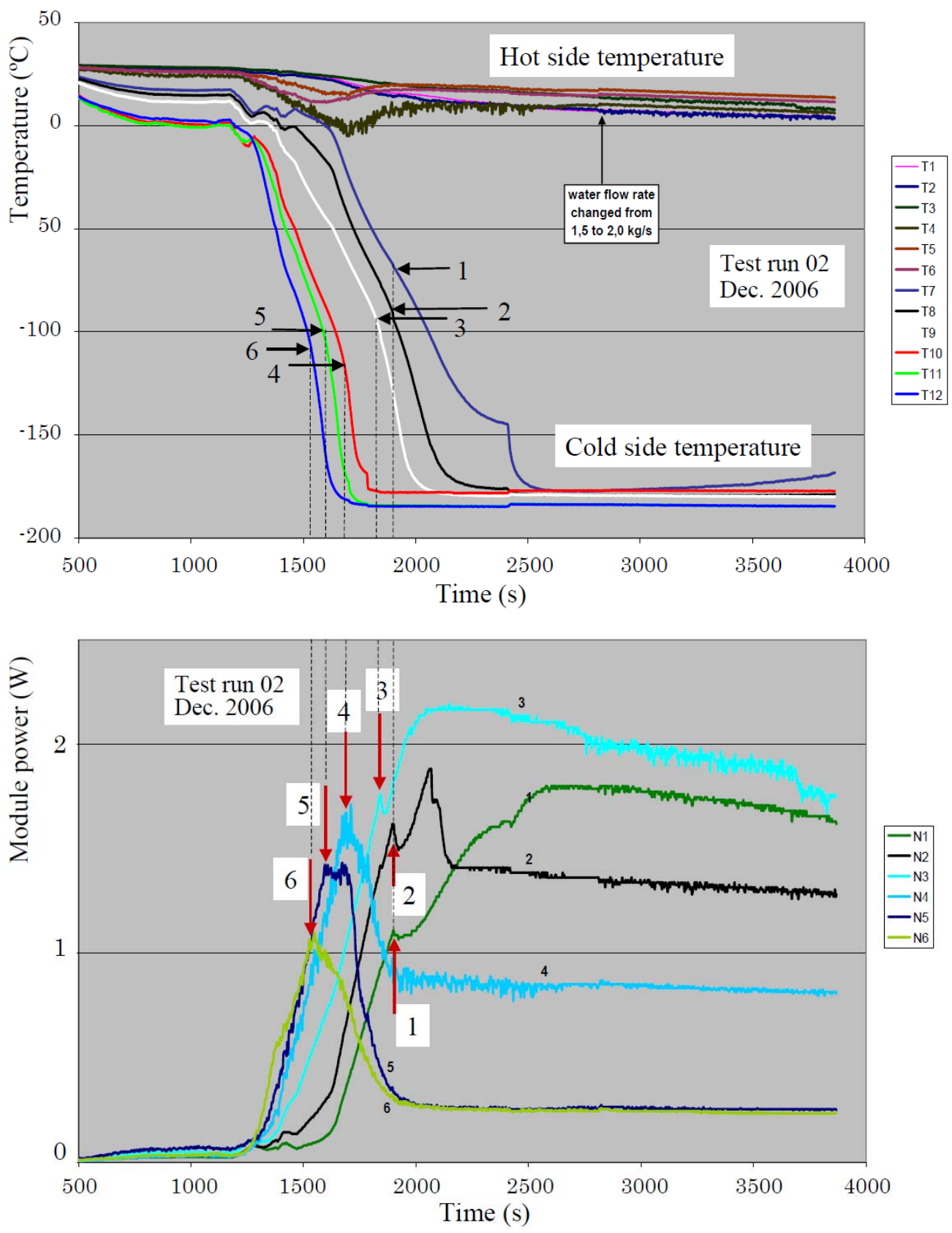

Fig.9 Module performance at the CTE test rig (Encapsulated modules L01-06)

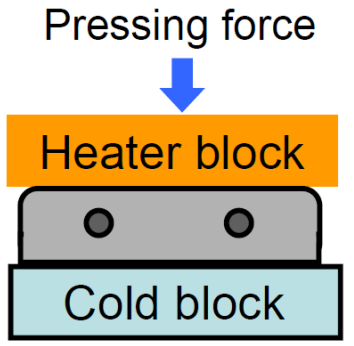

\section{Water flow}

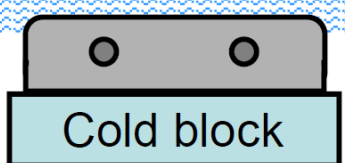

Fig.10 Schematic of the module performance test in the vacuum chamber (left) and the CTE test rig (right) 


\subsection{Investigation on the Mayer-Marschall efect}

As for the cause of the Mayer-Marschall effect, an attention was focused on the behavior of the ceramic base plate of the module in cryogenic temperature. Then the module L11 which presented this effect as shown in Fig. 4 was disassembled; TE semiconductors were removed from the ceramic base plate. Figure 11 shows the ceramic base plate $(40 \times 35 \times 1$ $\mathrm{mm}$ thick) on which spattered electrodes still exists. This plate was installed in the vacuum chamber (Fig. 3) which is identical to that used for the TE module measurement shown in Figs. 4-6. Then the hot side temperature was kept about $25^{\circ} \mathrm{C}$, while the other side was cooled down to $-196^{\circ} \mathrm{C}$ as shown in Fig. 12. When the cold side temperature reaches $-180^{\circ} \mathrm{C}$, the plate gave an acoustic signal "click" which could be heard even from the outside of the vacuum chamber. At this moment, temperature gradient became steeper due to increased thermal contact resistance at both side of the ceramic base plate. It seems that deformation of the ceramic base plate suddenly occurred under the severe thermal gradient in the thickness direction (over $200 \mathrm{~K} / \mathrm{mm}$ ) especially in the cryogenic temperature in which creep deformation can not be expected.

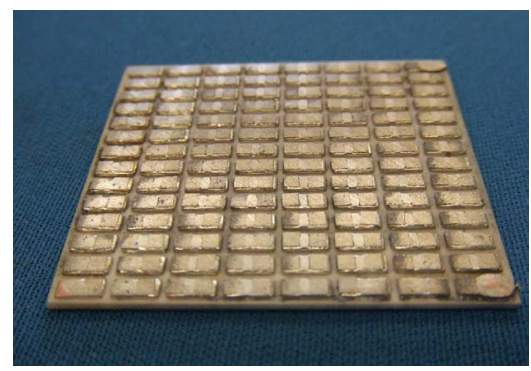

Fig.11 Base plate of the module L11

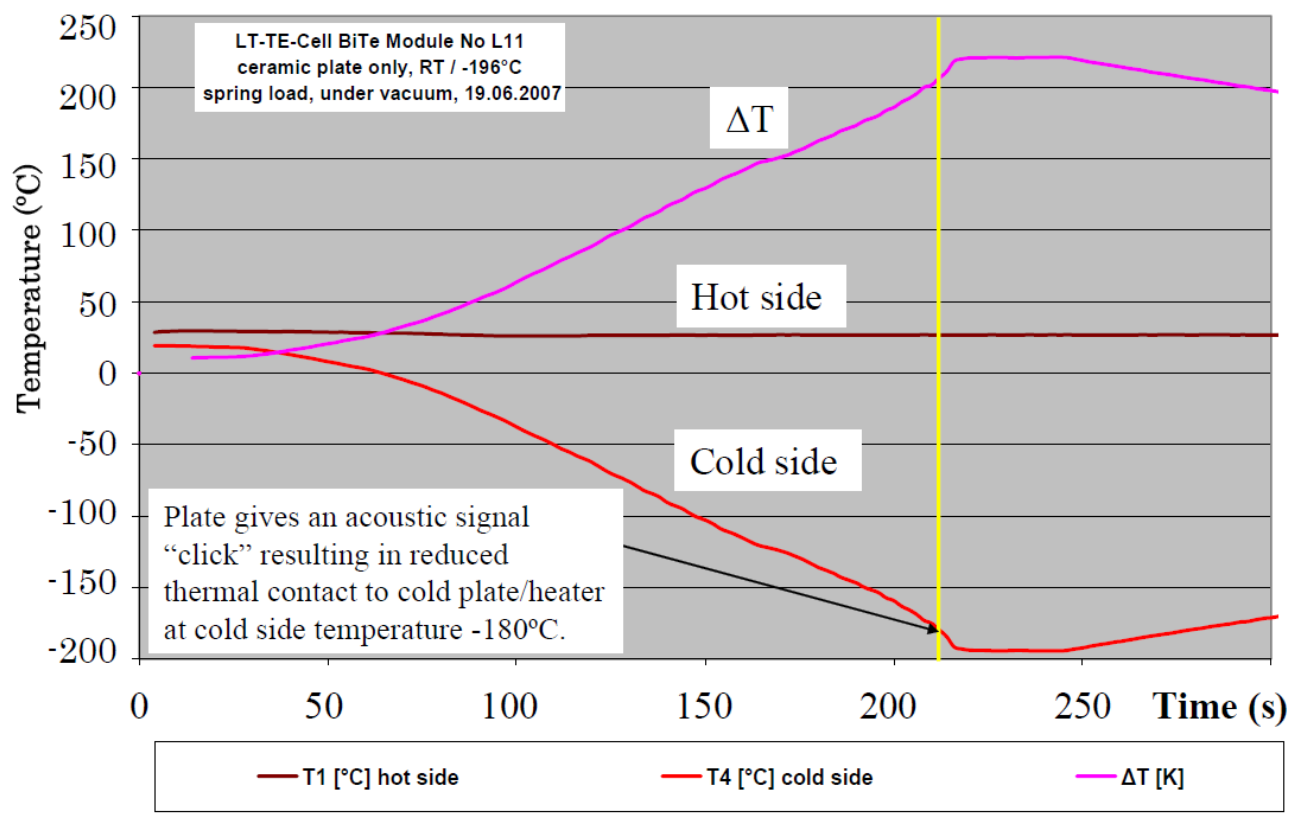

Fig.12 Cooling history of the base plate of module L11

Our next attempt was to conduct similar experiment using a raw ceramic plate $\left(\mathrm{Al}_{2} \mathrm{O}_{3}\right.$ $99.5 \%$, engineering ceramics, trade name F136) of the same dimension $(40 \times 35 \times 1 \mathrm{~mm}$ thick). A ceramic plate sample and the cooling history of this plate are shown in Figs. 13 and 14, respectively. Although an acoustic signal "click" can not be heard this time, temperature gradient became also steeper at the cold side temperature $-180^{\circ} \mathrm{C}$. Therefore we 
are sure that deformation of the ceramic plate suddenly occurred under the severe thermal gradient in the thickness direction.

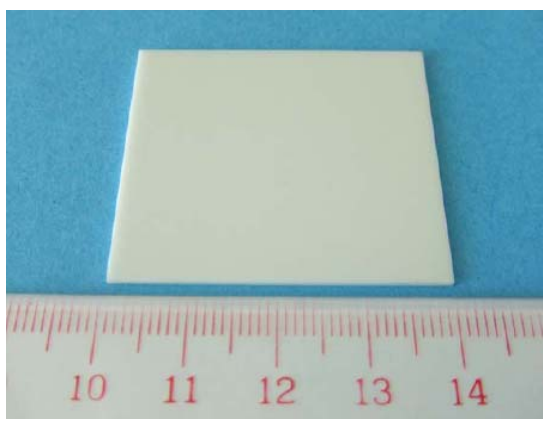

Fig.13 Ceramic plate

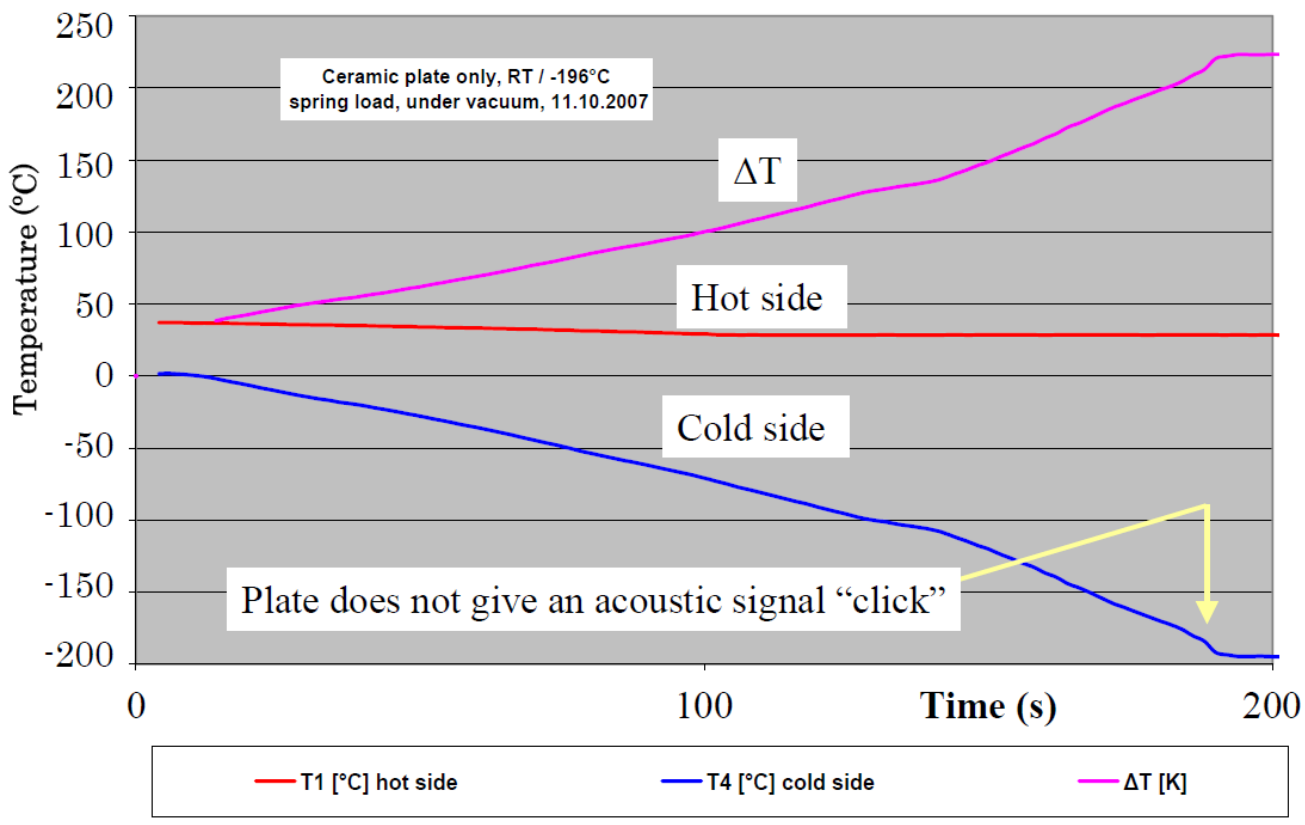

Fig.14 Cooling history of the ceramic plate

The investigation was then focused on the properties of the ceramic plate, especially on the thermal expansion modulus because it determines the thermal stress exerted on the ceramic plate by the following relations.

$$
\sigma=\varepsilon \mathrm{E}=\delta \Delta \mathrm{T} \mathrm{E}
$$

where

$$
\sigma: \text { thermal stress }
$$

$\varepsilon$ : unit elongation

E: Young's modulus

$\delta$ : thermal expansion modulus

$\Delta \mathrm{T}$ : thermal gradient in the thickness direction

The thermal expansion modulus of the ceramic plate in the range from $-190^{\circ} \mathrm{C}$ to 400 ${ }^{\circ} \mathrm{C}$ was measured by dilatometer.

If something happens at $-180^{\circ} \mathrm{C}$, e.g. transformation of the atomic texture, the thermal expansion modulus may drastically change. As shown in Fig. 15, however, the thermal expansion modulus increases smoothly as increasing temperature and nothing was found at $-180^{\circ} \mathrm{C}$. This coincides well with the fact that the Mayer-Marschall Effect occurs not at the 
definite temperature, but at wide temperature range (between -70 to $-180^{\circ} \mathrm{C}$ ) depending on the module situation. Therefore we conclude that only severe thermal gradient in the thickness direction (over $200 \mathrm{~K} / \mathrm{mm}$ ) of the ceramic base plate in the cryogenic temperature is the cause of the Mayer-Marschall effect.

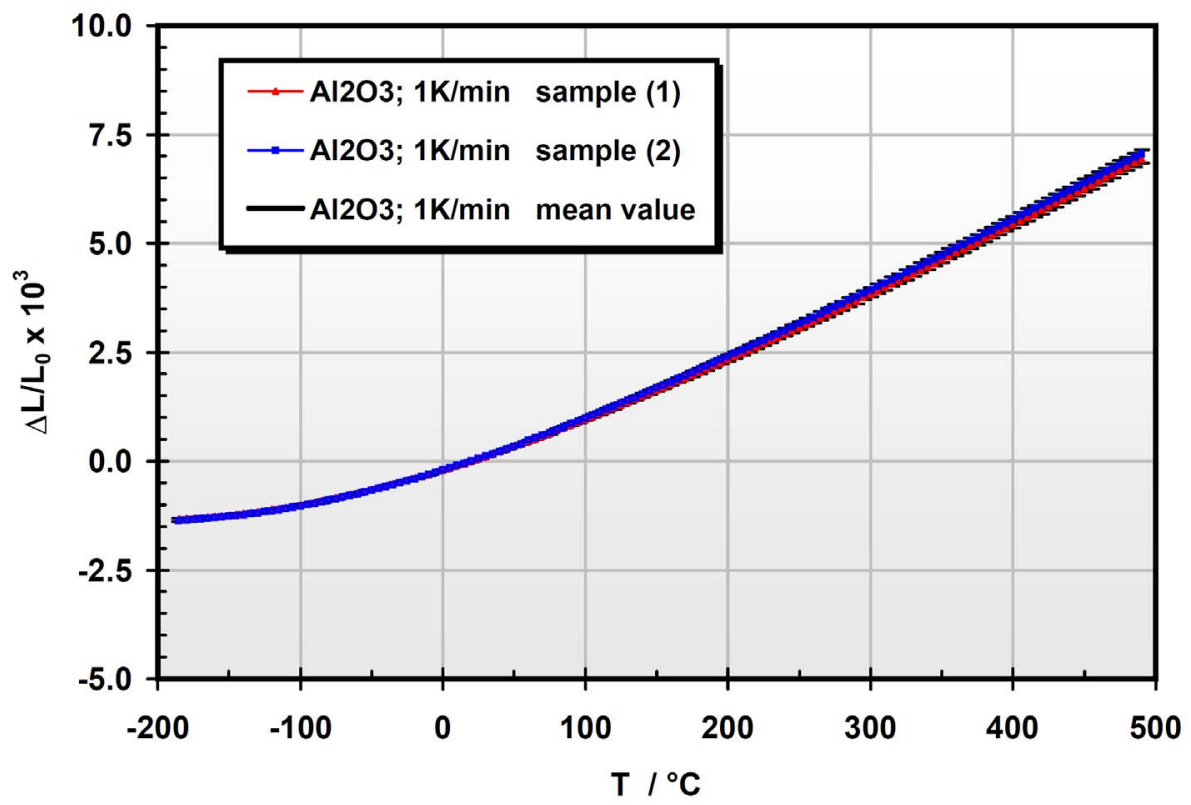

Fig.15 Thermal expansion modulus of the ceramic plate

Based on the investigation so far, mechanism of the Mayer-Marschall Effect is illustrated in Fig. 16. Deformation of the ceramic plate due to the severe thermal gradient in the thickness direction would result in increase of the thermal contact resistance of the TE module. Then the module power would be drastically reduced.

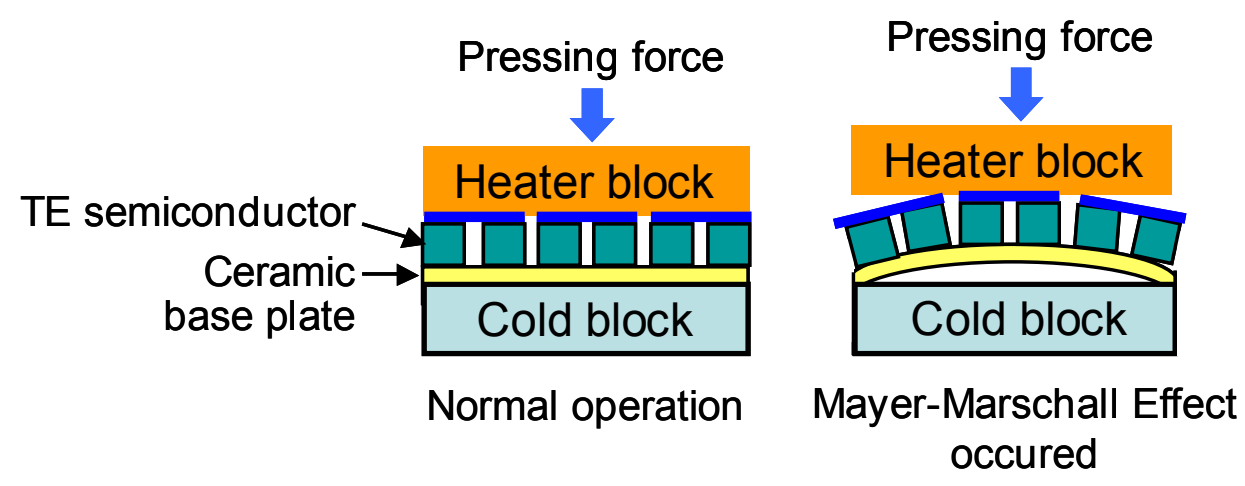

Fig.16 Mechanism of the Mayer-Marschall Effect 


\subsection{Performance of the modules that could avoid Mayer-Marschall effect}

The investigation so far revealed that the ceramic base plate may be responsible for the Mayer-Marschall effect. Then we focused attention on the performance of the modules adopted polymer (Figs. 17 and 19) and AlN (Fig. 18) base plates. In contrast with ceramic $\left(\mathrm{Al}_{2} \mathrm{O}_{3}\right)$, polymer has smaller Young's modulus, and AIN features greater thermal conductivity. Figure $\mathbf{1 7}$ shows a skeleton type polymer base BiTe module $(40 \times 35 \times 3 \mathrm{~mm}$ thick) of YAMAHA. The performance of this module in the vacuum chamber is shown in Fig. 20. The module power increases as increasing $\Delta \mathrm{T}$ and recorded $7.8 \mathrm{~W}$ at $\Delta \mathrm{T}=210 \mathrm{~K}$.

This module was then encapsulated and again subjected to the measurement in the vacuum chamber. The result is shown in Fig. 21. Due to the existence of thermal resistance of the container itself, the encapsulated module power is $85 \%$

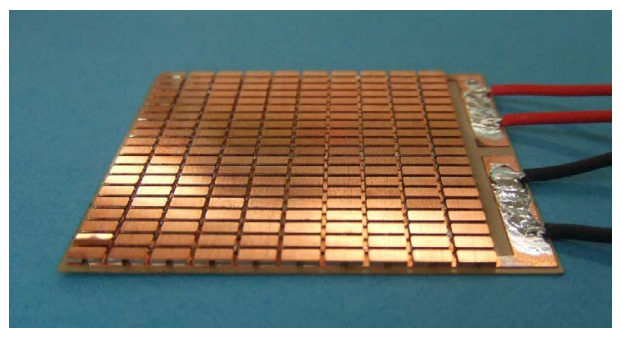

Fig.17 Skeleton type polymer base BiTe module (YAMAHA)

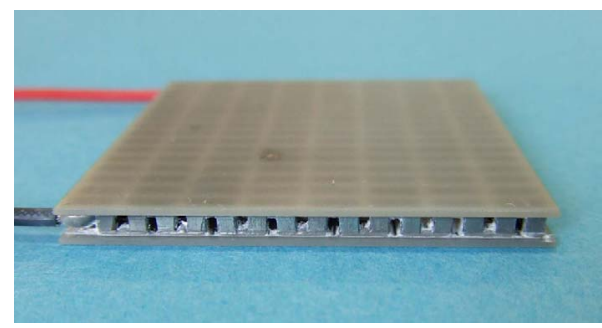

Fig.18 AlN base BiTe module (Ferrotec)

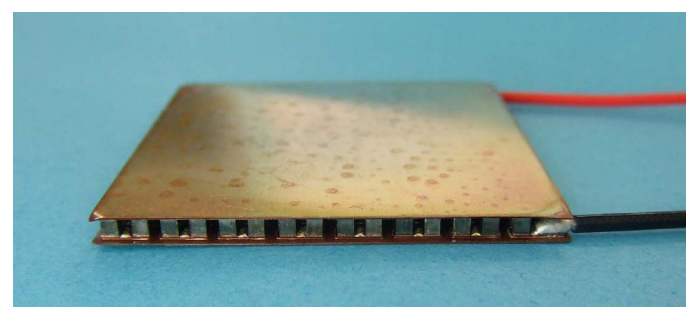

Fig.19 Polymer base BiTe module (Ferrotec) of that without container. This coincides well with our former experiment ${ }^{1)}$. An AIN base and a polymer base modules of Ferrotec (both dimensions: $40 \times$ $40 \times 3 \mathrm{~mm}$ thick, without container) were also measured in the vacuum chamber. Results are shown in Figs. 22 and 23, respectively. All these modules presented favorable performance. No module suffered the Mayer-Marschall effect. Therefore we concluded that severe thermal gradient in the thickness direction (over $200 \mathrm{~K} / \mathrm{mm}$ ) of the ceramic base plate in the cryogenic temperature is the cause of the Mayer-Marschall effect.

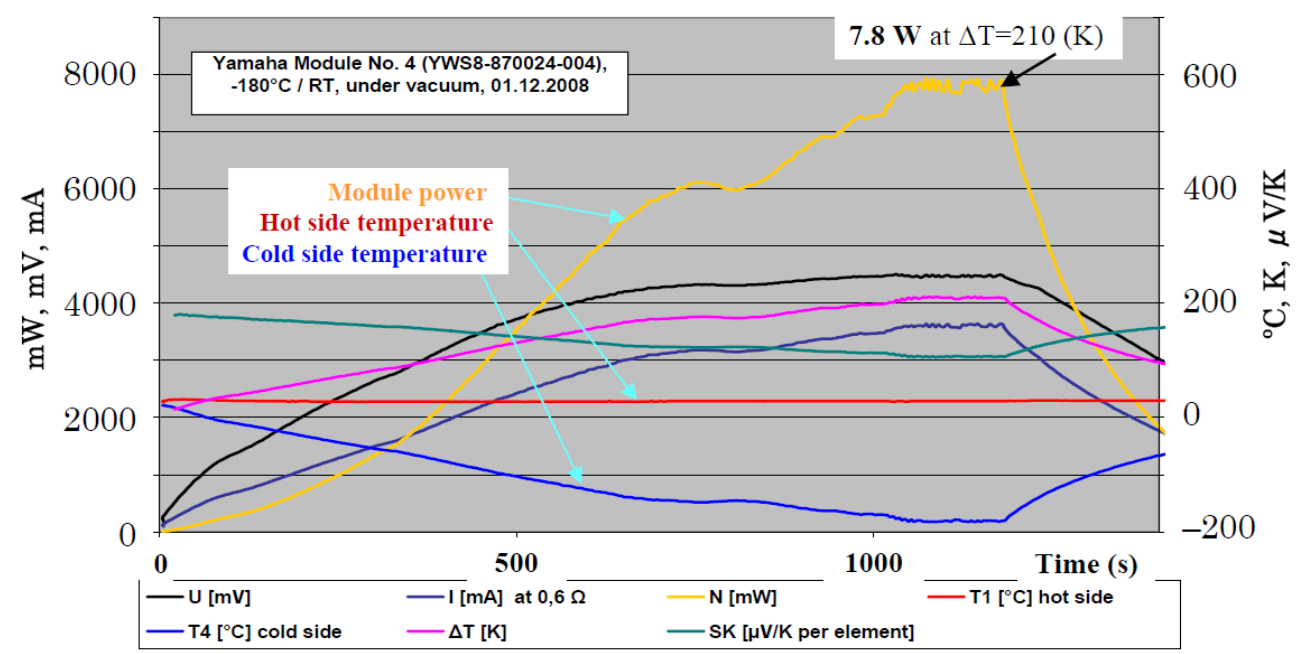

Fig.20 Module performance (YAMAHA polymer base module No.4) 


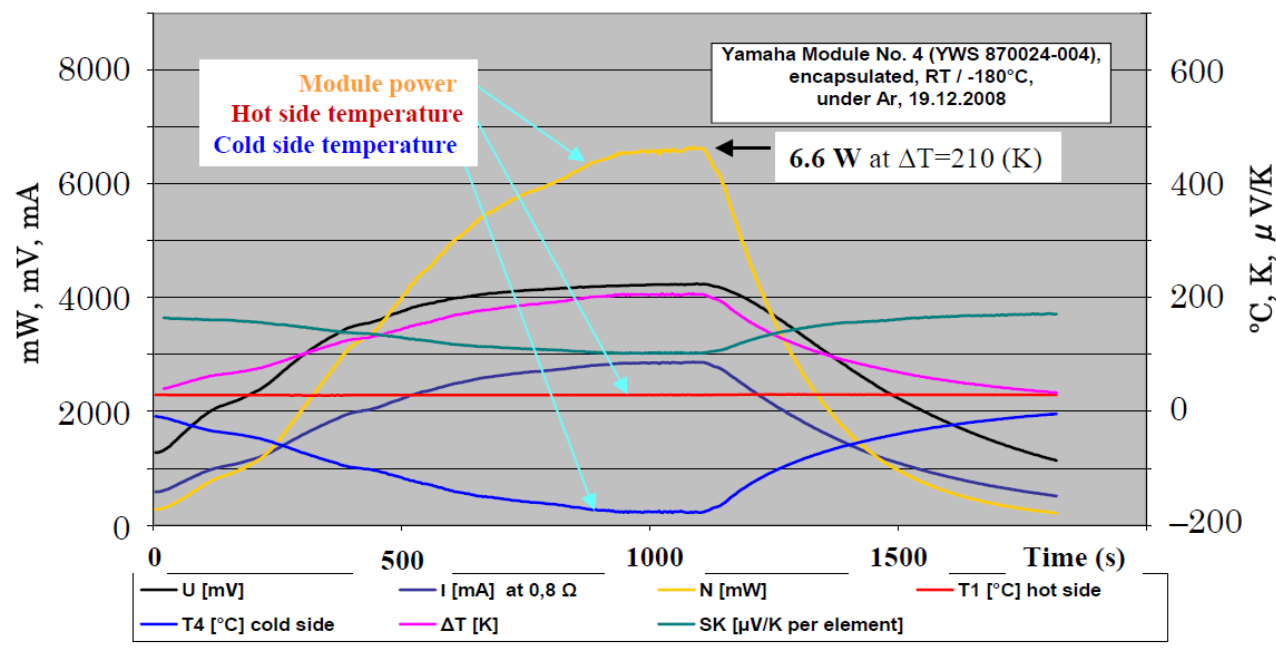

Fig.21 Encapsulated module performance

(YAMAHA polymer base module No.4)

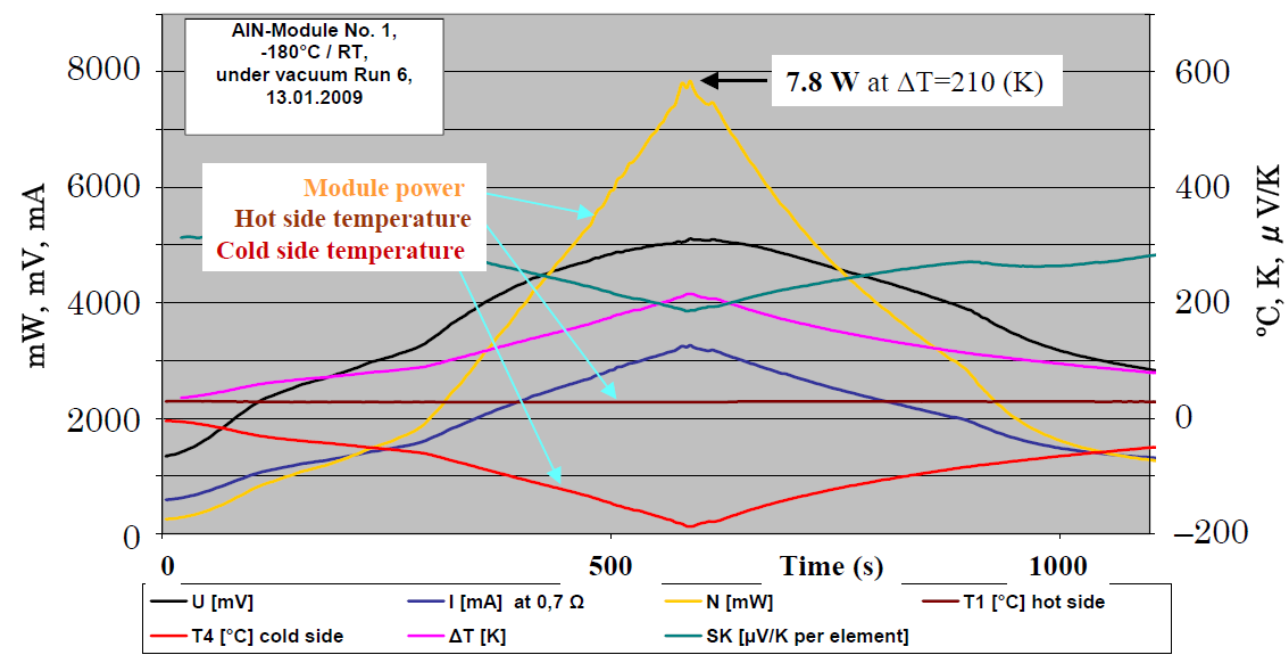

Fig.22 Module performance (Ferrotec AlN base module)

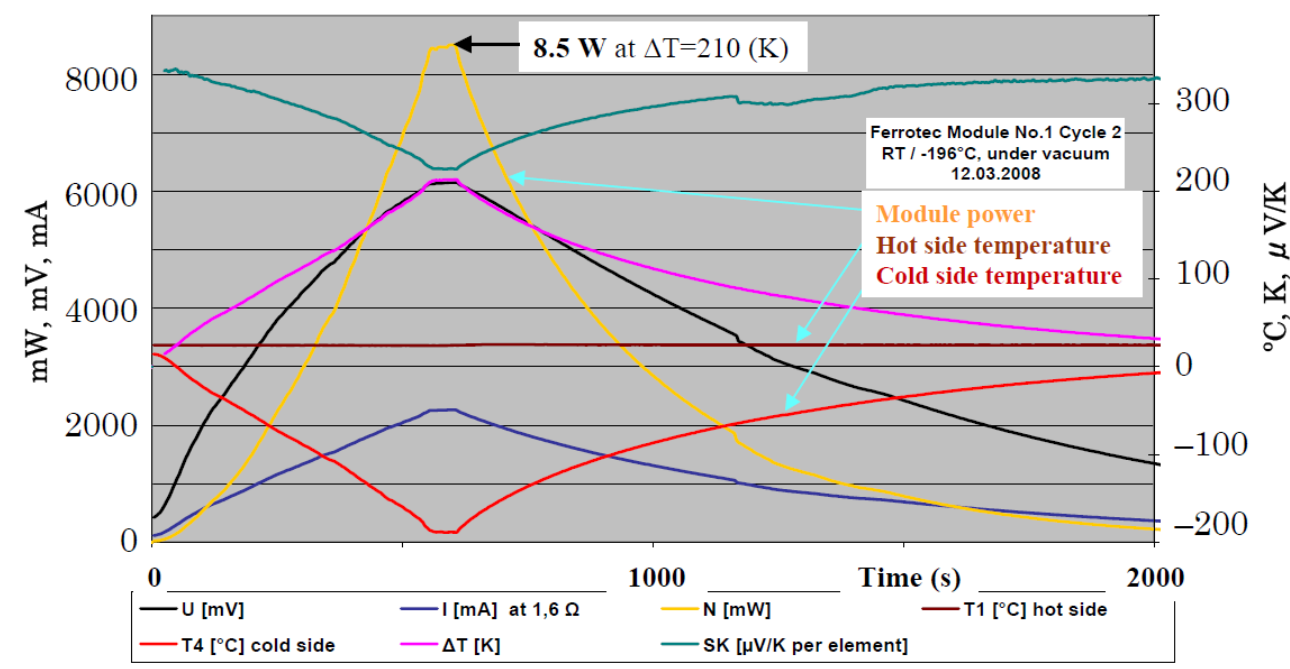

Fig.23 Module performance (Ferrotec polymer base module) 


\section{Encapsulated module performance at the small CTE test rig}

As shown in the preceding chapter, polymer base and AlN base modules do not suffer the Mayer-Marschall effect. Among such modules, the encapsulated polymer base modules of YAMAHA was installed in the small CTE (cryogenic thermoelectric) test rig which can realize temperature condition of the open rack vaporizer.

The small CTE test rig is shown in Fig. 24. It consists of a test section and a horizontal acrylic cylinder of $30 \mathrm{~cm}$ diameter and $1 \mathrm{~m}$ long to which water circulation is possible by an external pump. The test section is made of a rectangular aluminum tube covered by a thermal insulation, with a liquefied nitrogen inlet, a $\mathrm{N}_{2}$ gas outlet and instrumentations. An encapsulated TE module and a dummy module (only containers without TE modules) are attached on the aluminum tube. As a thermal insulation, filler material which solidifies by chemical reaction, trade name Zelupur manufactured by Zelu Chemie GmbH was adopted. This is a thermal insulation widely adopted for housing construction and automobile industry. Power cables of the TE module as well as water proof connectors are sealed in the thermal insulation layer. Together with the thermal insulation, the top of the TE module container has a flat surface so as that water is well stabilized and flows perfectly over the TE module. Although the water flow velocity is not simulated in the small CTE test rig, it is sufficient to achieve actual TE module situation (refer to Fig. 10) where water exerts pressing force of 1 bar $(0.1 \mathrm{MPa})$ instead of a rigid heater block. An advantage of the small CTE test rig over the conventional CTE test rig (Figs. 7 and 8) is that the former requires less preparation time and running cost.

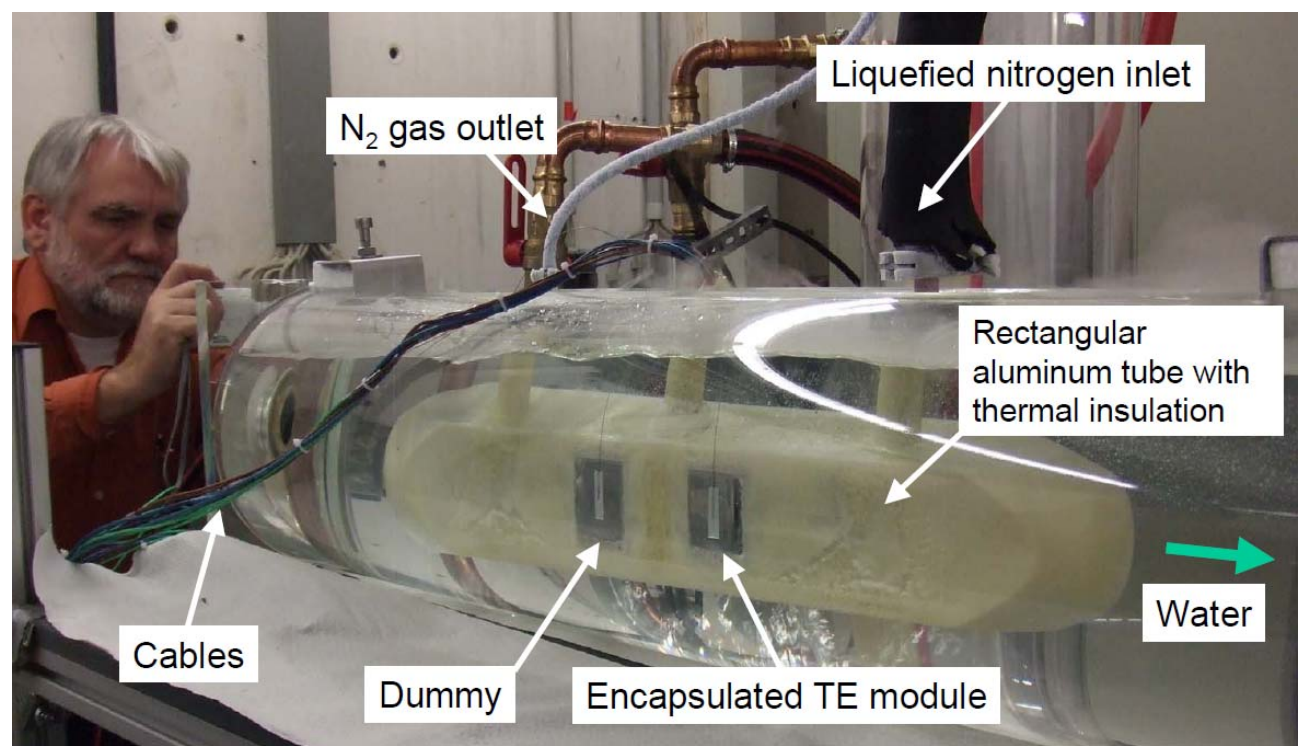

Fig.24 Small CTE test rig

The performance of the encapsulated polymer base module of YAMAHA (No.4) in the small CTE test rig is shown in Fig. 25. Test has been conducted by circulating water of room temperature around the tube while supplying liquefied nitrogen into the tube, then module power increases as increasing $\Delta \mathrm{T}$ and the Mayer-Marschall effect did not occur. A slight fluctuation of the module power in Fig. 25 is due to the noise from the water circulating pump and nothing to do with the actual module power. Therefore we are sure that severe thermal gradient in the thickness direction (over $200 \mathrm{~K} / \mathrm{mm}$ ) of the ceramic base plate in the cryogenic temperature is the cause of the Mayer-Marschall effect.

The encapsulated TE module provides electrical power of $2.2 \mathrm{~W}$ at $\Delta \mathrm{T}=120 \mathrm{~K}$ and 2.4 $\mathrm{W}$ at $\Delta \mathrm{T}=140 \mathrm{~K}$. As discussed in our former paper ${ }^{1)}$, the operating temperature of the 
encapsulated module in our proposed design is; container hot side $-2^{\circ} \mathrm{C}$ and cold side $-142^{\circ} \mathrm{C}(\Delta \mathrm{T}=140 \mathrm{~K})$ at the bottom of the TE module section, and container hot side $0^{\circ} \mathrm{C}$ and cold side $-120^{\circ} \mathrm{C}(\Delta \mathrm{T}=120 \mathrm{~K})$ at the top of the TE module section. Due to restriction of the small CTE test rig, water temperature was about $30 \mathrm{~K}$ higher than that of the proposed design, however, it is not so important because module power is roughly proportional to the square of the temperature difference while not significant change is foreseen on the BiTe properties in such a slight temperature shift. The electrical power of the module available at small CTE test rig is lower than that measured in the vacuum chamber $(3.0 \mathrm{~W}$ at $\Delta \mathrm{T}=120 \mathrm{~K}$ and $4.0 \mathrm{~W}$ at $\Delta \mathrm{T}=140 \mathrm{~K}$, as shown in Fig. 21) due to the difference of pressing force exerted on the module as illustrated in Fig. 10.

Similar test result of the encapsulated ceramic base module at the CTE test rig is reported in the former paper ${ }^{1)}$. This module often suffered the Mayer-Marschall effect as shown in Fig. 9, however, provided electrical power of $2.0 \mathrm{~W}$ at $\Delta \mathrm{T}=120 \mathrm{~K}$ and $2.1 \mathrm{~W}$ at $\Delta \mathrm{T}=140 \mathrm{~K}$ so long as the Mayer-Marschall effect did not occur. Therefore the encapsulated polymer base module tested this time provided slightly better electrical power $(2.2 \mathrm{~W}$ at $\Delta \mathrm{T}=120 \mathrm{~K}$ and $2.4 \mathrm{~W}$ at $\Delta \mathrm{T}=140 \mathrm{~K}$ ), and most of all, presented no Mayer-Marschall effect.

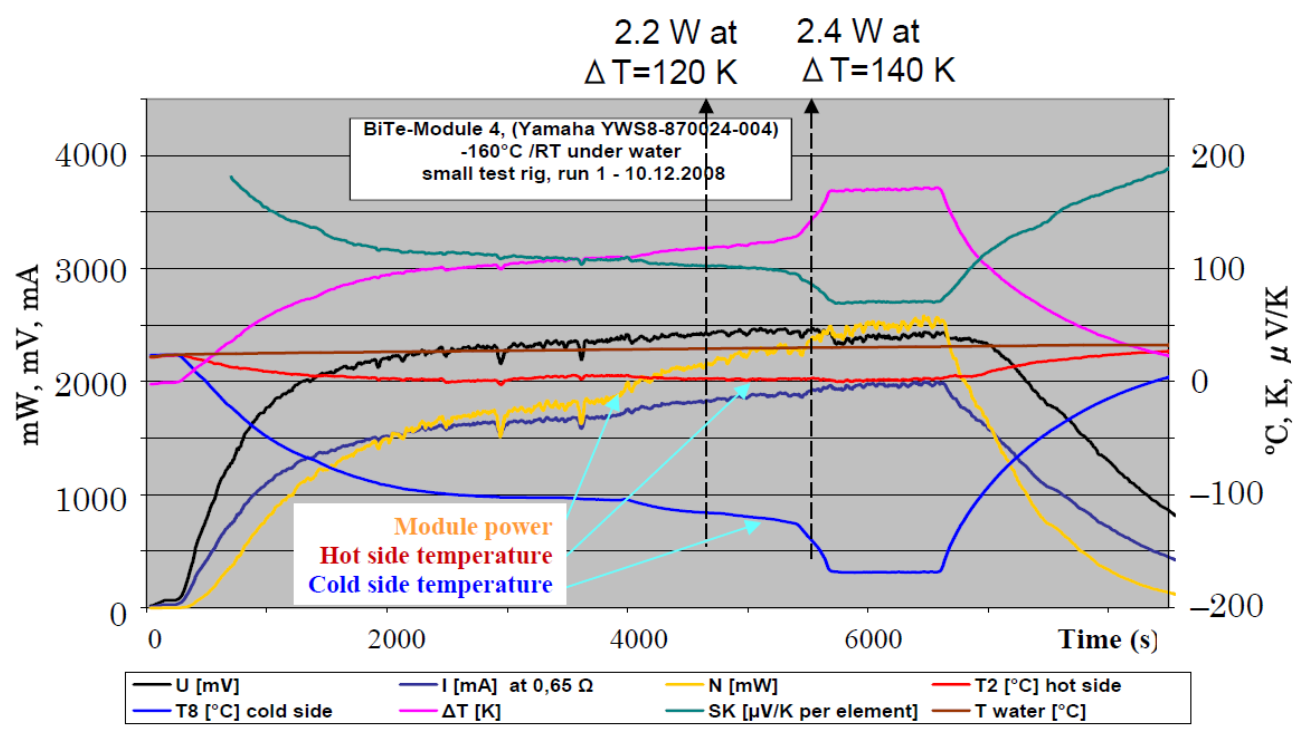

Fig.25 Encapsulated module performance at the small CTE test rig (YAMAHA polymer base module No.4)

\section{Conclusions}

In the development of the TE power conversion system combined with open rack type LNG vaporizer (ORV), the authors found that most of the conventional BiTe TE modules suffer sudden decrease of the power at cryogenic temperature as low as $-160^{\circ} \mathrm{C}$. This is called as Mayer-Marschall effect. Authors investigated the cause of this effect and found TE modules that could avoid such effect.

The following results are obtained.

1) Severe thermal gradient in the thickness direction (over $200 \mathrm{~K} / \mathrm{mm}$ ) of the ceramic base plate of the TE module in the cryogenic temperature is the cause of the Mayer-Marschall effect.

2) A polymer base and AlN base modules do not suffer the Mayer-Marschall effect because polymer has smaller Young's modulus and AlN features greater thermal conductivity. 
The TE power conversion systems adopted a polymer base or AlN base modules combined with open rack type LNG vaporizer (ORV) could provide electrical power with a reasonable cost as estimated in our former paper ${ }^{1)}$.

\section{Acknowledgments}

The authors wish to acknowledge the contribution of H. G. Mayer, and R. Marschall of KE-Technologie GmbH of the Stuttgart University as finders of the Mayer-Marschall effect. The research described in the chapter 2.1 and 2.2 was conducted by the joint research project of CRIEPI, The Kansai Electric Power Co., Inc. and Kobe Steel Ltd. While the activities shown in the chapter 2.3 and 3 were done by CRIEPI internal funding support.

\section{References}

[1] Kambe, M., Morita, R., Omoto, K., Koji, Y., Yoshida, T. and Noishiki, K., “Thermoelectric Power Conversion System Combined with LNG Vaporizer," Journal of Power and Energy Systems, Paper No. 08-0479, Vol.2, No.6, pp.1304-1319, July 2008.

[2] Shikata, H. and Kambe, M., "Development of Advanced Thermoelectric System for Belt-driven Furnaces and Incinerators," NEDO Technical Report, 2007, http://www.tech.nedo.go.jp/servlet/HoukokushoKensakuServlet?db=n\&kensakuHoho= Barcode_Kensaku\&SERCHBARCODE $=100010933$.

[3] Goto, M., Shinkai, K., Egashira, S. and Konishi, K., "SUPERORV Development and Marketing," R-D Kobe Steel Engineering Reports, Vol. 53, No. 2, September 2003. 